\title{
A Steam Ejector Refrigeration System Powered by Engine Combustion Waste Heat: Part 2. Understanding the Nature of the Shock Wave Structure
}

\author{
Yu Han ${ }^{1,2}$, Xiaodong Wang ${ }^{1, *}$, Lixin Guo ${ }^{1}$, Anthony Chun Yin Yuen ${ }^{2}{ }^{(}$, , Hengrui Liu ${ }^{2} \mathbb{D}$, \\ Ruifeng Cao ${ }^{2}$, Cheng Wang ${ }^{2} \odot$, Cuiling $\mathrm{Li}^{1}$, Jiyuan $\mathrm{Tu}^{3}{ }^{-}$and Guan Heng Yeoh ${ }^{2,4}$ \\ 1 School of Mechanical Engineering \& Automation, Northeastern University, Shenyang 110819, China; \\ yu.han4@student.unsw.edu.au (Y.H.); Lixinguo.neu@outlook.com (L.G.); clli@mail.neu.edu.cn (C.L.) \\ 2 School of Mechanical and Manufacturing Engineering, University of New South Wales, NSW 2052, Australia; \\ c.y.yuen@unsw.edu.au (A.C.Y.Y.); h.liu@unsw.edu.au (H.L.); ruifeng.cao@unsw.edu.au (R.C.); \\ c.wang@unsw.edu.au (C.W.); g.yeoh@unsw.edu.au (G.H.Y.) \\ 3 School of Engineering, RMIT University, Melbourne, VIC 3083, Australia; jiyuan.tu@rmit.edu.au \\ 4 Australian Nuclear Science and Technology Organization (ANSTO), Locked Bag 2001, Kirrawee DC, \\ NSW 2232, Australia \\ * Correspondence: xdwang@mail.neu.edu.cn; Tel.: +86-24-8368-7618
}

Received: 17 September 2019; Accepted: 16 October 2019; Published: 19 October 2019

\begin{abstract}
In general, engine fuel combustion generates 30\% waste heat, which is disposed to the environment. The use of the steam ejector refrigeration to recycle the waste heat and transfer them to useful energy source could be an environmentally friendly solution to such an issue. The steam ejector is the main component of the ejector refrigeration system, which can operate at a low-temperature range. In this article, the internal shock wave structure of the ejector is comprehensively studied through the computation fluid dynamics (CFD) approach. The shock wave structure can be subdivided into two regions: firstly the pseudo-shock region consisting of shock train and co-velocity region; secondly the oblique-shock region composed of a single normal shock and a series of oblique shocks. The effect of the shock wave structure on both pumping performance and the critical back pressure were investigated. Numerical predictions indicated that the entrainment ratio is enhanced under two conditions including (i) a longer pseudo-shock region and (ii) when the normal shock wave occurs near the outlet. Furthermore, the system is stabilized as the back pressure and its disturbance is reduced. A critical range of the primary fluid pressure is investigated such that the pumping is effectively optimized.
\end{abstract}

Keywords: combustion waste heat; steam ejector; shock wave; entrainment ratio; pumping performance; critical back pressure

\section{Introduction}

The steam ejector refrigeration system has been well-recognized to be a very promising device in saving energy and reducing and environmental pollution [1]. The steam ejector refrigeration system was firstly proposed by Maurice Leblanc in 1910. Even since there was a gradual decline in research attention due to its low cooling efficiency [2]. As an important means of transportation in today's social development, the energy consumption and environmental pollution of automobiles have always been the concern of researchers. The traditional compression refrigeration systems may not meet the requirements of increasing awareness and pressure to protect the environment. Recently, 
owing to the low-grade energy (i.e., waste heat) from the engine combustion waste heat can be used as power consumption in the ejector refrigeration system, steam ejector refrigeration systems have regained its research interests in particularly on the optimization of energy conversion [3]. As the main component of the refrigeration system, the steam ejector is designed to be simply structured without any rotational parts, for the purpose of stable operation, long service life and low maintenance cost [4]. The ejector is mainly composed of a nozzle, a mixing section, a constant-area section and a subsonic diffuser section [5]. The efficiency of the ejector is affected by both the geometric and operating parameters. Nevertheless, the further improvement of the ejector pumping efficiency requires a deeper understanding of its internal flow structure and the fluid characteristics [6].

The research on the ejector is mainly carried out from two aspects: experiment and numerical simulation. Numerous experimental efforts on the ejector refrigeration system have been made to enhance the understanding of the flow structure, thus enhancing the design of the system. The choking of the secondary fluid in the mixing chamber had an important influence on the pumping performance of the ejector, and the maximum COP(the coefficient of performance) is obtained under the critical flow condition studied by Eames et al. $[2,7,8]$. These important conclusions were the theoretical foundations of future research on the steam ejector. Chen et al. [6] established a steam ejector refrigeration system to evaluate the performance of ejectors under different operating. The corresponding empirical equations were deduced according to the experimental results. Chunnanond et al. [9] measured the pressure along the wall of the ejector to examine the influence of operating and geometry parameters on the performance of the ejector. By analysing the experimental results, the expansion angle, effective area and shock wave were obtained to explain the flow characteristics of the two fluids and the mixing process inside the ejector. A solar-powered ejector refrigeration system with a movable spindle at the inlet of the primary nozzle was built to adjust the pumping performance of the ejector by changing the pressure of the boiler [10-12]. It was discovered that the position of the spindle greatly influences the entertainment ratio and the critical back pressure.

Similarly, the variable-area ejector refrigeration system was established by Chandra and Ahmed [13] in 2014. The results indicated that the variable-area ejector eliminated the loss of the total pressure caused by the shock wave and the efficiency of the system was improved. Ramesh and Sekhar $[14,15]$ analysed the effect of suction chamber angle and different NXP (i.e., nozzle exit position) on the entrainment ratio of the steam ejector using the experimental method. The conclusion was that the entrainment ratio increased with the increasing of the suction chamber angle and decreased with a decline of the NXP. $\mathrm{Li}$ et al. [16] established an experimental device of the ejector refrigeration system using R134a as the refrigerant to investigate the influence of the operating parameters and the area ratio of the mixing chamber on the performance of the ejector. Dong et al. $[1,17]$ conducted different experiments under three nozzle ejectors with a different cross-section area. A certain structure of a steam ejector was found to enable the ejector refrigeration system work in a heat source temperature between $40^{\circ} \mathrm{Cand} 70{ }^{\circ} \mathrm{C}$. Śmierciew et al. [18] established an experimental ejector refrigeration system driven by low-grade energy of $55^{\circ} \mathrm{C}$ using HFO-1234ze(E), as the working fluid.

Computational fluid dynamics (CFD) method is widely used in the study of the steam ejector owing to its comprehensive analytical potential benefit by the visualization [19], as well as the advantages of prediction for the flow dynamic behavior [20]. It not only can predict and reflect the flow characteristics inside the ejector but also can estimate the pumping efficiency of the ejector. Besides, the complex and non-linear turbulent effect on the fluid structure can be characterized to evaluate the mixing process and the wall shearing behaviours [21-23]. The simulation study of geometric parameters were mainly in terms of nozzle structure [24], the area ratio of nozzle throat to constant-area section [25,26], the NXP (nozzle exit position) [27-29], diffusion angle [30] and the structure of mixing chamber [31]. The influence of five different nozzle geometry on the flow characteristics inside the ejector was studied by Yang et al. [32]. The results showed that the increase of ER can be achieved by increasing the exit perimeter and the special geometric structure. Ruangtrakoon et al. [33] discussed the effect of eight different primary nozzle structure on the ejector refrigeration performance. Riffat and 
Omer [34] analysed the influence of the NXP on the performance of the ejector and obtained the optimal geometry of the ejector using the methanol as the working fluid. The variation of pumping performance with a variable primary nozzle geometry was discussed by Varga et al. [11]. Sriveerakul et al. [35,36], Yuan et al. [26] and Aly et al. [37] comprehensively analysed and discussed the variation of the pumping performance under different geometric and operating parameters. A better understanding of the mixing process of the working steam and the pumped steam under different back pressure was studies by Su and Agarwal [38]. According to the work of Dong et al. [27], a higher COP can be obtained by decreasing the temperature of primary steam and raising the temperature of secondary steam.

In Part 1, the flow structure characteristics of the entire fluid in the steam ejector were analysed meanwhile, the correctness and applicability of the CFD model were verified. Since the primary fluid stream drives additional flows via the secondary inlet, it significantly improves the overall momentum across the ejector and outlet thrust. With the utilization of pressurized steam as the primary fluid, such a system can be potentially applied for automobile cooling system. Nonetheless, the optimization of the pumping efficiency of the steam ejector has always been the major consideration in the design of ejector refrigeration systems. Different from other devices with one converging-diverging structure, there were two converging-diverging structures in a typical steam ejector, one was in the nozzle, and the other was in the subsonic diffuser. The primary fluid is accelerated into the supersonic fluid in the primary nozzle. The primary fluid is mixed with the suction steam and discharged into the condenser through the pressure difference in the subsonic diffuser. Due to the unique, plain structure of the ejector, the flow structure of the fluid in the ejector is also complex, such as transonic flow [15], choking flow [39], shock train [40], boundary layer separation [41], shock-mixing layer [42] and the pseudo shock $[40,43]$, etc. Shock waves are generated during the transonic fluid flow. When a shock wave contacts with the boundary layer, a shock-mixing layer structure will be formed. Simultaneously, the shock wave would exert a strong pressure gradient on the boundary layer that can result in the boundary layer thicker to separate from the wall and to increase the fluid viscous dissipation. Though the shock wave is a common structure occurring in different fluid flows, the influence on the steam ejector cannot be ignored because the existence of the shock wave makes the flow structure of the ejector more complex and varied. However, there are few works focused on analysing the whole shock wave structure inside the ejector comprehensively. The better understanding of the shock wave structure would be helpful to improve the ejector efficiency and optimize the geometric structure of the ejector. In enlighten of the current knowledge gap, the shock wave structure of flow structure inside the steam ejector is entirely studied through the numerical simulation method in this article. The shock wave structure is identified and sub-divided into two regions based on physical observation of the flow via simulation results. Three types of the shock waves inside the steam ejector are classified and defined. The influence of the shock wave structure on the pumping performance of the steam ejector under different primary fluid pressure is discussed.

\section{Numerical Algorithms}

\subsection{Governing Equations}

The flow of the steam ejector is controlled by the conservation equation of the compressible steady-state asymmetric fluid flow [44]. Typically, the Navier-Stokes equation can be applied for thermally driven variable-density flow, as the turbulent interactions are conveniently accounted in the momentum and energy equations [45,46]. The total energy equation including viscous dissipation and the set coupled with the ideal gas law [47]. The thermodynamic and transport properties of steam remain unchanged during validation. The governing equations of the continuity equation, the momentum equation and the energy equation can be written as follows:

The continuity equation:

$$
\frac{\partial \rho}{\partial t}+\frac{\partial}{\partial x_{i}}\left(\rho u_{i}\right)=0
$$


The momentum equation:

$$
\frac{\partial}{\partial t}\left(\rho u_{i}\right)+\frac{\partial}{\partial x_{j}}\left(\rho u_{i} u_{j}\right)=-\frac{\partial P}{\partial x_{i}}+\frac{\partial \tau_{i j}}{\partial x_{j}}
$$

The energy equation:

$$
\frac{\partial}{\partial t}(\rho E)+\frac{\partial}{\partial x_{i}}\left(u_{i}(\rho E+P)\right)=\vec{\nabla} \cdot\left(\alpha_{e f f} \frac{\partial T}{\partial x_{i}}\right)+\vec{\nabla} \cdot\left(u_{j}\left(\tau_{i j}\right)\right)
$$

where

$$
\tau_{i j}=\mu_{e f f}\left(\frac{\partial u_{i}}{\partial x_{j}}+\frac{\partial u_{j}}{\partial x_{i}}\right)-\frac{2}{3} \mu_{e f f} \frac{\partial u_{k}}{\partial x_{k}} \delta_{i j}
$$

With

$$
\rho=\frac{P}{R T}
$$

where $\tau_{i j}$ is the stress tensor, $E$ is the total energy, $\alpha_{e f f}$ is the effective thermal conductivity, and $\mu_{e f f}$ is the effective molecular dynamic viscosity.

\subsection{Geometry and Mesh Approach}

The geometry of the ejector is derived from the experimental system described in Part 1 . In order to reduce the calculation cost and running time, a two-dimensional axisymmetric model is adopted in this work. The geometric parameters of the ejector are shown in Table 1.

Table 1. Geometrical parameters of the steam ejector.

\begin{tabular}{cc}
\hline Geometrical Parameters & Value \\
\hline Diameter of the nozzle inlet & $12 \mathrm{~mm}$ \\
Diameter of the nozzle outlet & $11 \mathrm{~mm}$ \\
Diameter of the nozzle throat & $2.5 \mathrm{~mm}$ \\
Expand the angle of the nozzle & $10^{\circ}$ \\
Nozzle exit position & $10 \mathrm{~mm}$ \\
Diameter of the mixing chamber inlet & $70 \mathrm{~mm}$ \\
Diameter of the throat & $28 \mathrm{~mm}$ \\
Length of the mixing chamber & $122.2 \mathrm{~mm}$ \\
Length of the throat & $90 \mathrm{~mm}$ \\
Length of the subsonic diffuser & $210 \mathrm{~mm}$ \\
\hline
\end{tabular}

The structured meshing of the internal flow field of the ejector is carried out. Encryption is carried out in the region with high local speed. The specific grid structure after adaptive technology is shown in Figure 1. The grid quality is above 0.9 , and the maximum aspect ratio is $5: 1$. The grid quality is high enough to meet the requirements of numerical simulation. By comparing the Mach number distribution curves of the centerline under different grid densities in Figure 2, the variation trend of the medium grid and the fine grid is almost the same. The Mach number has reached mesh independence by using a medium grid. Therefore, the medium grid is adopted in the subsequent simulation process with the grid number of 47,562 units. 


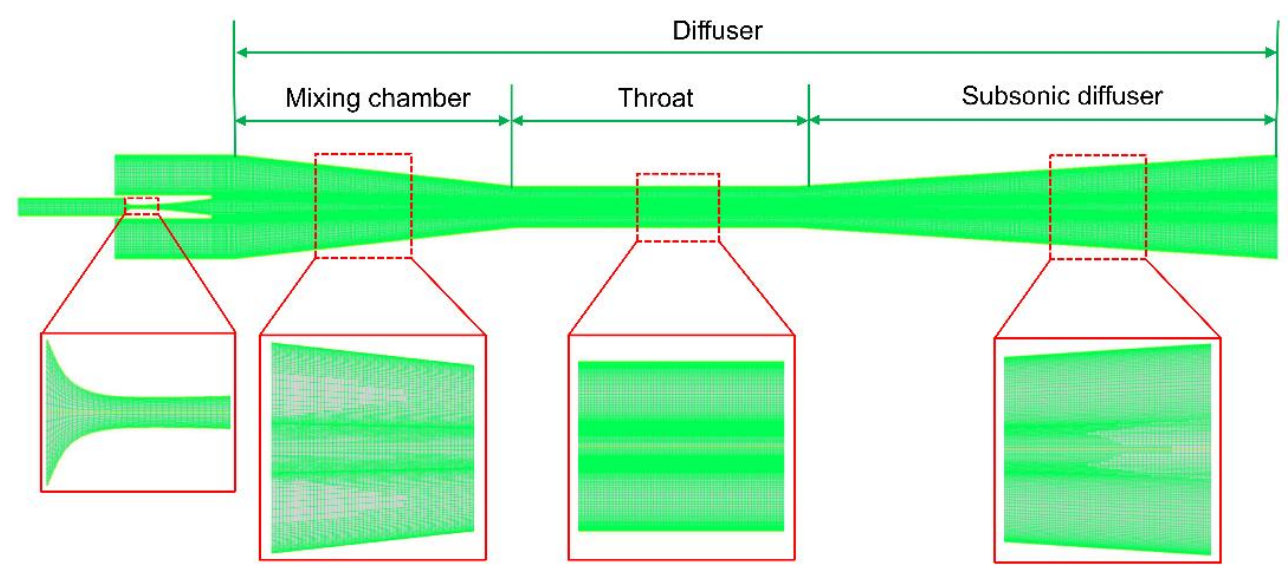

After Adaptation

Figure 1. The mesh structure of the steam ejector.

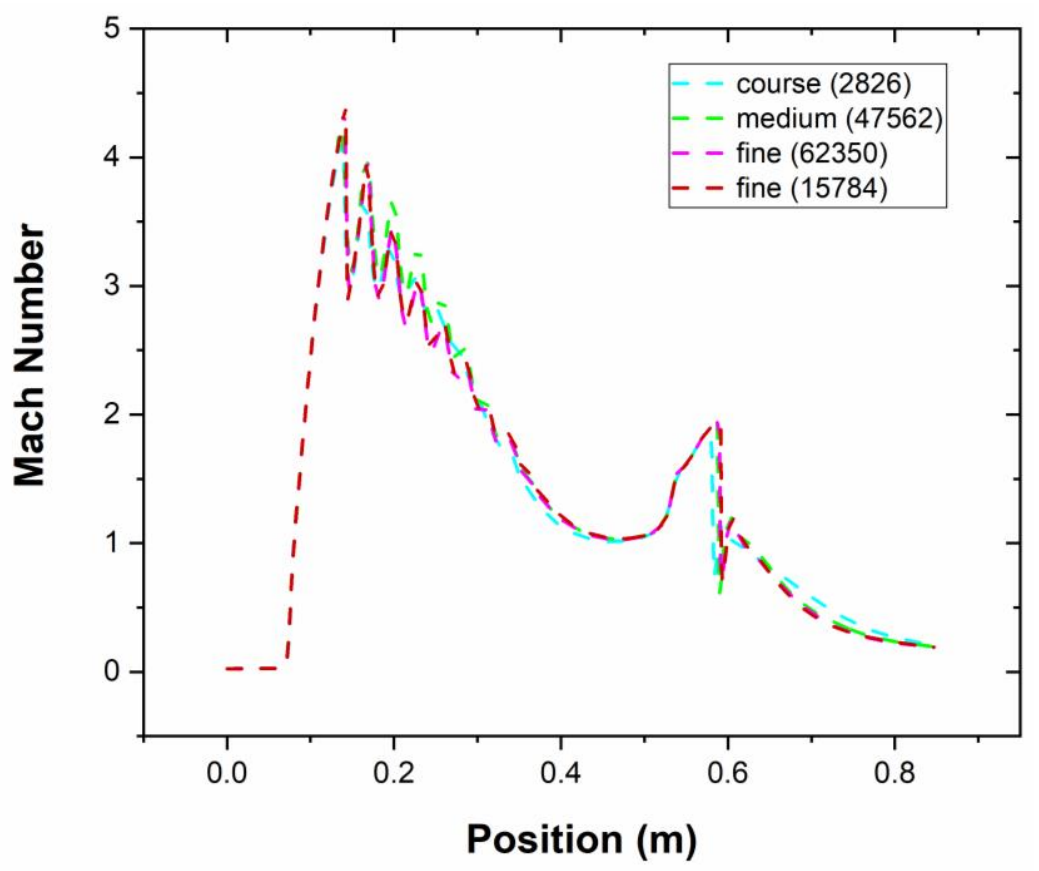

Figure 2. Grid independence verification.

\subsection{Numerical Solution Procedure}

The computational fluid dynamics software FLUENT19.2 based on ANSYS was used for simulation analysis. As mentioned in Part 1, with the application of the segregated solver and the pressure is simulated by pressure velocity coupling approaches [48,49]. The coupled implicit solver is used, and the diffusion term is discretized by the central difference scheme, to enhance the thermal and molecular diffusion for thermally driven reacting flows [45]. The field variables values are closed by Gauss-Seidel iteration method and subsequentially march in the time by multiple Runge-Kutta explicit schemes. All the convection terms are discretized using the second-order upwind scheme. The k-w SST turbulence model is applied for the consideration of turbulent interaction with the flow field, which can predict the complex flow in the ejector. The wall is considered as adiabatic isentropic flow with no-slip condition. To include the wall damping effect on turbulence, the near-wall treatment method uses the enhanced wall function with $y<0.893[50,51]$. The turbulence intensity at the entrance is $5 \%$. The inlet and outlet are set as pressure inlet and pressure outlet, respectively. Besagni $G$ et al. $[41,52,53]$ have proved that the density of the vapour is not much different from the real gas model to the ideal gas model. Therefore, 
the ideal gas model is used to simplify the problem. The properties of water vapour are shown in Table 2 . The operating conditions of the numerical simulations are displayed in Table 3.

Table 2. Properties of the working fluid used in the simulation.

\begin{tabular}{ccccc}
\hline Properties & $\begin{array}{c}\text { Dynamic } \\
\text { Viscosity }\end{array}$ & $\begin{array}{c}\text { Thermal } \\
\text { Conductive }\end{array}$ & $\begin{array}{c}\text { Specific } \\
\text { Heat Capacity }\end{array}$ & $\begin{array}{c}\text { Molecular } \\
\text { Weight }\end{array}$ \\
\hline \multirow{2}{*}{ Value } & $\begin{array}{c}1.34 \times 10^{-5} \\
\mathrm{kgm}^{-1} \mathrm{~s}^{-1}\end{array}$ & $\begin{array}{c}0.00261 \\
\mathrm{Wm}^{-1} \mathrm{~K}^{-1}\end{array}$ & $\begin{array}{c}2014.00 \mathrm{~J} \\
\mathrm{~kg}^{-1} \mathrm{~K}^{-1}\end{array}$ & $\begin{array}{c}18.01534 \\
\mathrm{kgkmol}^{-1}\end{array}$ \\
\hline
\end{tabular}

Table 3. The operating conditions of the numerical simulation.

\begin{tabular}{cc}
\hline Operating Condition & Value \\
\hline Primary fluid pressure & $360,000 \mathrm{~Pa}$ \\
Secondary fluid pressure & $2330 \mathrm{~Pa}$ \\
Back pressure & $3500 \mathrm{~Pa}$ \\
\hline
\end{tabular}

\section{Results and Discussion}

\subsection{Structural Division of Shock Wave Structure in the Ejector}

The efficiency of the ejector is mainly determined by the degree of the mixing process between the primary fluid and the secondary fluid, as discussed in Part 1. Another important aspect affecting the pumping performance of the ejector is the complex flow characteristics of the steam ejector produced. Among these flow characteristics, the shock wave structure is extremely complex and its structure is one of the factors to determine the pumping performance of the steam ejector [40]. However, there is still a less thorough understanding of the whole shock wave structures in detail. This section will analyse and discuss the shock waves inside the steam ejector.

The Mach number contour of the flow field and the static pressure distribution curve of the wall and the axis of the ejector are shown in Figure 3. The whole shock wave structure in the steam ejector can be clearly observed. The static pressure at the axis of the mixing chamber fluctuates up and down due to the existence of a series of shock waves in the mixing chamber and the throat sections. The zone ranges from the beginning point $A$ of the shock wave to the point $B$ where the two static pressure curves coincide is called the shock train region which is separated by the choking position of the secondary fluid. The range of this region is the length of the primary fluid jet core as described in Part 1 . The pressure along the wall of the pseudo-shock region changes relatively smoothly, but the pressure along the axis continues to oscillate and its amplitude gradually decreases until the point $\mathrm{B}$. The zone which ranges from the first coincidence point $A$ to the second coincidence point $C$ is called the co-velocity region. The pressures and the velocities are constant and the two streams begin to mix with each other. The shock train and the co-velocity region are collectively referred to as a pseudo shock region [43] while the oblique-shock region consisting of a single normal shock wave and a series of oblique shocks [40], and the range of which is from the position of the normal shock wave to the coincidence point $C$.

From the Mach number cloud diagram of the steam ejector in Figure 4a, it can be clearly seen that three types of shock waves exit in the whole flow field. One type is the shock train consisting of several diamond waves both in the mixing chamber and the throat sections as displayed in Part 1, the other type is a single inviscid normal shock wave in the subsonic diffuser section. The last type is the oblique shock following with the normal shock. Figure 4a displays the Mach number counter of the ejector when the primary fluid pressure, secondary fluid pressure and the back pressure are $0.36 \mathrm{MPa}$, $2330 \mathrm{~Pa}$ and $3500 \mathrm{~Pa}$, respectively. As indicated by the Mach number distribution along the radial distance shown in Figure $4 \mathrm{~b}$, the larger change of the velocity gradient begins at $0.50 \mathrm{~m}$ distance along the wall. When the distance is greater than $0.50 \mathrm{~m}$ on the $\mathrm{X}$-axis, greater velocity fluctuation occurs near the wall showing that the normal shock wave starts to change into the oblique shock waves [40]. 
The oblique shock waves are generated after the $0.5 \mathrm{~m}$, which corresponds to the Mach number contour in Figure 4a. The intensity of oblique shock wave reaches its maximum at $0.51 \mathrm{~m}$ and keeps constant between $0.52 \mathrm{~m}$ and $0.54 \mathrm{~m}$. The results show that the bifurcation structure is generated at the root of the positive shock with the decrease of the Mach number values. Then, the oblique shock is formed. The energy of the primary jet core decreases which resulting in the separation degree of the boundary layer becomes stronger, and the mixing degree of the two streams is sufficiently affected. The efficiency of the steam ejector will decline with the non-fully mixing process between the two streams.

Figure 5 shows the Mach number distribution curve along the ejector axis. The Mach number values fluctuate continuously. There are six peak values and six trough values in the shock train region. However, there is only one inviscid normal shock wave in the subsonic diffuser section with only one peak value. It shows that the shock train is composed of the bifurcation shock waves causing the fluid oscillations. The concrete manifestation is that the static pressure along the axis drops first and then remains constant while the velocity increases first and then decreases, as shown in Figures 3 and 5. That indicates the shock train plays an important role in restoring pressure in the case of some energy loss. Therefore, the shock train area can be judged and defined according to the fluctuation range and oscillation amplitude of the pressure or the velocity.

In the subsonic diffuser section, a single normal shock wave appears near the outlet of the throat section, which is generally accompanied by the transonic behaviour and followed by a subsonic region. The normal shock wave can prevent the disturbance caused by the change of the back pressure propagating upstream. When the position of the normal shock wave is closer to the outlet of the subsonic diffuser, the critical back pressure is higher, the influence of the back pressure is less and the system operation will be more stable. However, a few oblique shock waves with small amplitude following by the normal shock wave are generated, which would reduce the energy exchange of the mixing process between the two streams [54]. The oblique shock region composing of the normal shock wave and a series of the bifurcated shock waves are different from the pseudo-shock region composed by the shock train and the co-velocity region. The former will prevent the disturbances caused by the back pressure from propagating upstream. The latter is an important area for mixing of the two streams. Moreover, the shock wave structures are the main components of the entire flow structure inside the ejector.

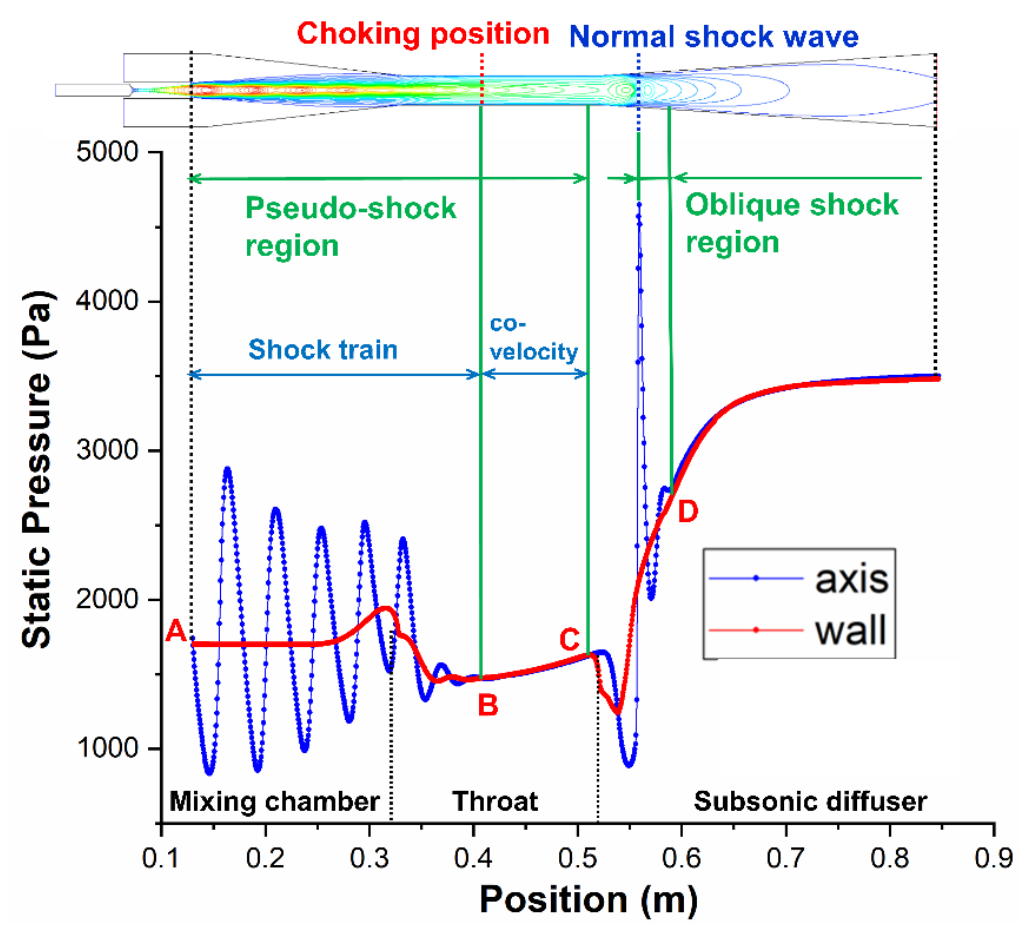

Figure 3. The structure of shock wave in the steam ejector. 


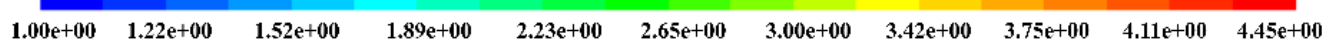

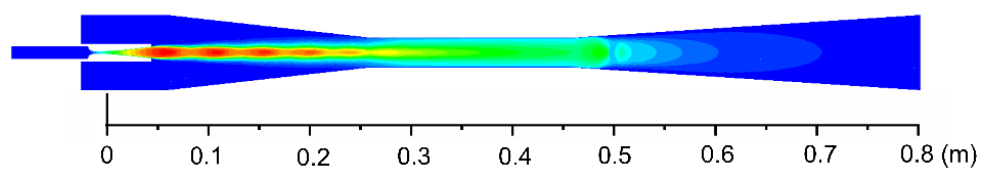

(a)

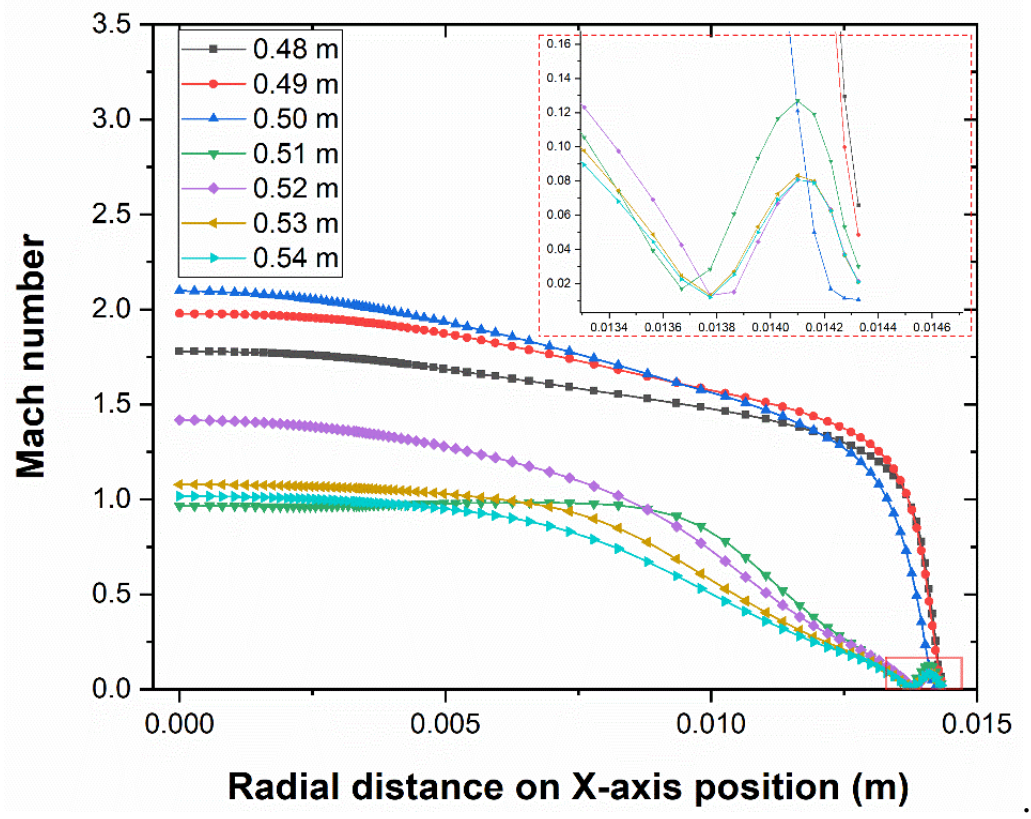

(b)

Figure 4. (a) The contour of Mach number at the primary fluid pressure; (b) Radial distance on different $\mathrm{X}$-axis position.

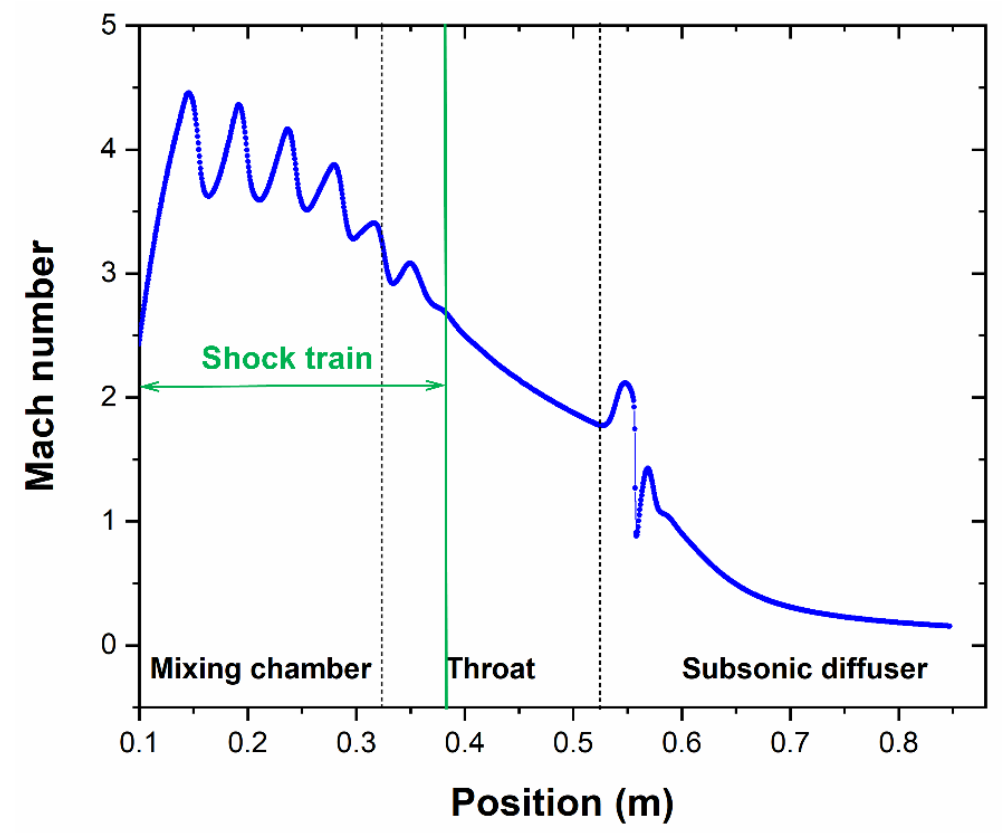

Figure 5. The distribution curve of Mach number at centerline. 


\subsection{Effect of the Shock Wave Structure on the Pumping Performance}

Under the condition of the secondary fluid, pressure is $2330 \mathrm{~Pa}$ and the back pressure is $3500 \mathrm{~Pa}$, the pumping performance of the steam ejector with changing of the primary fluid pressure is analysed. The contour of Mach number above 1 under different primary fluid pressure is shown in Figure 6 . The structure and characteristics of the shock wave can be clearly observed. An oblique-shock region consisting of a normal shock wave and a series of bifurcated shock waves represented in the dashed box. The velocity of the mixed fluid suddenly drops from supersonic to subsonic due to the existence of the normal shock wave. To accurately capture the shock wave position, only fluids above 1 Mach number are displayed and the subsonic part would not appear. It can be seen that the higher the primary fluid pressure is, the closer the normal shock wave is to the outlet of the ejector. While the length of the oblique-shock in the subsonic diffuser section increases with the increasing of the primary fluid pressure. The flow region in the throat section where the fluid velocity is higher than 1 Mach number expands. The length of the pseudo-shock strain is elongated with the increase of the primary fluid pressure when the primary fluid pressure is less than $0.34 \mathrm{MPa}$. When the pressure is more than $0.34 \mathrm{MPa}$, the length of the pseudo-shock region maintains constant. It shows that the energy and momentum of the primary fluid mixing with the secondary fluid continuously increases when the primary fluid pressure is less than $0.34 \mathrm{MPa}$. However, the increase of the oblique shock region consumes a part of the energy and momentum of the mixed fluid causing the energy of the mixed fluid to be reduced when it flows through this region. The shock wave structure changes significantly from the inviscid normal shock to the bifurcation oblique shock with the primary fluid pressure increasing. When the primary fluid pressure is less than or equal to $0.34 \mathrm{MPa}$, the upstream Mach number values and the intensity of the shock wave decrease. At $0.34 \mathrm{MPa}$, the velocity at the center of the shock wave is the highest. When the primary fluid pressure is more than $0.34 \mathrm{MPa}$, the upstream Mach number values of the shock wave rises significantly, and the normal shock changes to be a bifurcated oblique shock.

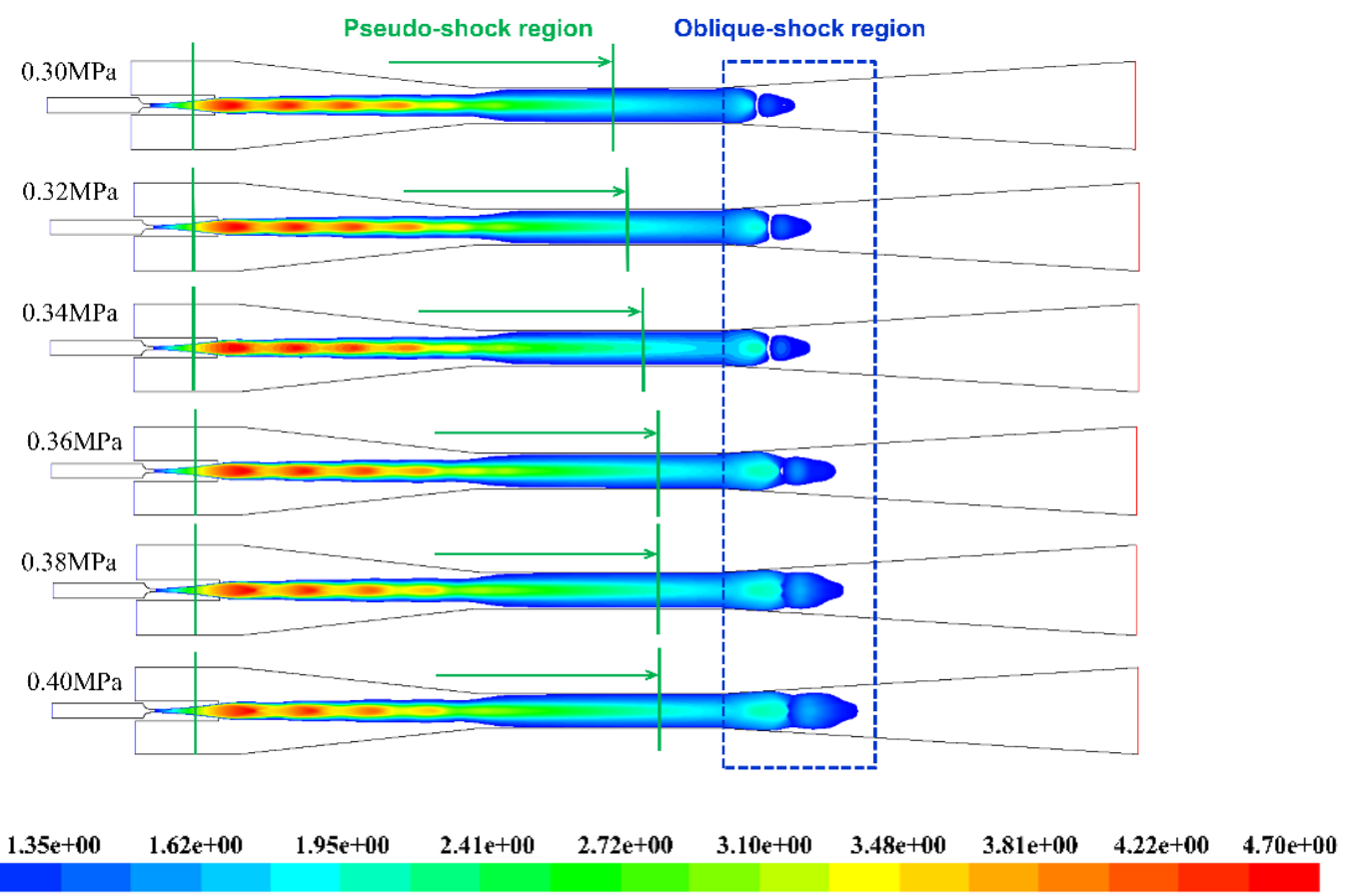

Figure 6. The influence of primary fluid pressure on the shock structure.

Figure 7 shows the Mach number distribution curve at the axis of the ejector to illustrate the influence of the oblique-shock region. The Mach number values of the fluid in the mixing chamber section is significantly higher than that in the subsonic diffuser section. When the Mach number in 
the subsonic diffuser section reaches 4.26 , a shock train is generated. When the Mach number value is less than 1.53, a series of oblique shock waves are formed and accompanied by the transonic flow behaviour. As long as there is a normal shock wave in the subsonic diffuser section, the ejector is in the double-choked flow mode [55] with a better pumping performance. When the normal shock wave enters the throat section, the double-choked flow mode would be destroyed by the downstream back-pressure disturbance. The pumping performance of the ejector continuously decreases until it loses its function completely. It shows that the normal shock wave is of great significance in maintaining the pumping performance and the operational stability of the ejector.

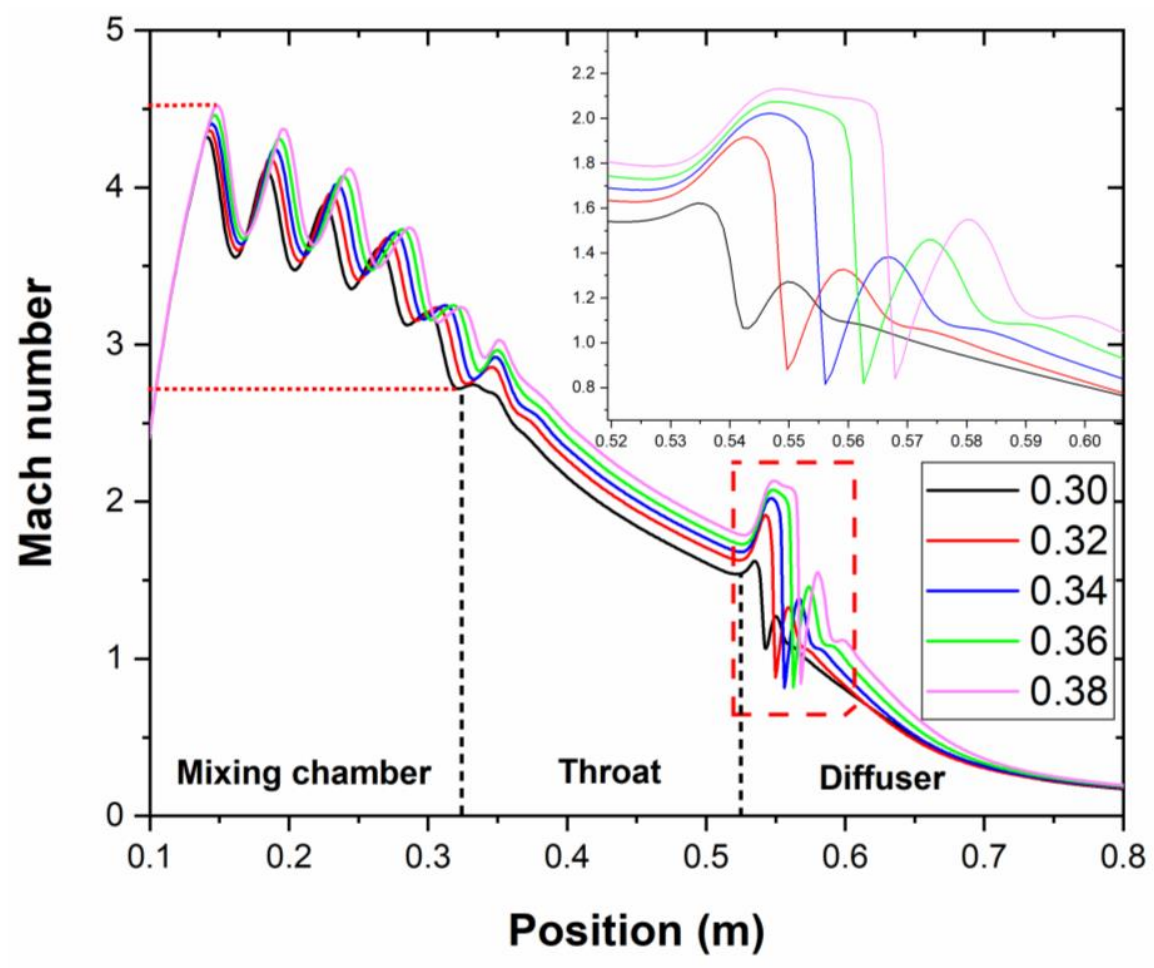

Figure 7. The curve of Mach number along the axis under different primary fluid pressure.

The variation of the entrainment ratio under different primary fluid pressure is shown in Figure 8. The experimental and simulation values of the entrainment ratio are in a good agreement. The entrainment ratio reaches the optimum value at $0.34 \mathrm{MPa}$. The entrainment ratio is more than 0.8 when the primary fluid pressure is at between $0.32 \mathrm{MPa}$ and $0.36 \mathrm{MPa}$, while it is less than 0.8 when the primary pressure is outside of this range. As displayed in Figure 7, when the primary fluid pressure is between $0.32 \mathrm{MPa}$ and $0.36 \mathrm{MPa}$, the Mach number values at the subsonic diffusion section is between 1.6 and 2.1. The peak Mach number value is 2.1 at $0.34 \mathrm{MPa}$. It indicates that when the primary fluid pressure is $0.34 \mathrm{MPa}$, the normal shock wave with more energy makes the mixing of two streams more completely and the mixed fluid with a higher pressure can effectively prevent the disturbance generated by the back. Simultaneously, the energy loss of the shock wave at the entrance of the subsonic diffuser section is the smallest when the primary pressure is at $0.34 \mathrm{MPa}$. As the primary fluid pressure is greater than $0.34 \mathrm{MPa}$, the front area of the normal shock wave becomes wider (in Figure 7), and the intensity of the normal shock wave becomes weak (in Figure 6). The velocity gradient generated at the wall surface will lead to the boundary layer separation. The partial energy and momentum of the mixed fluid will be lost, and the entrainment ratio will be reduced. When the primary fluid pressure is less than $0.34 \mathrm{MP}$, the mixing process of the two streams is not enough resulting in a smaller entrainment ratio because of the normal shock wave within less energy. 


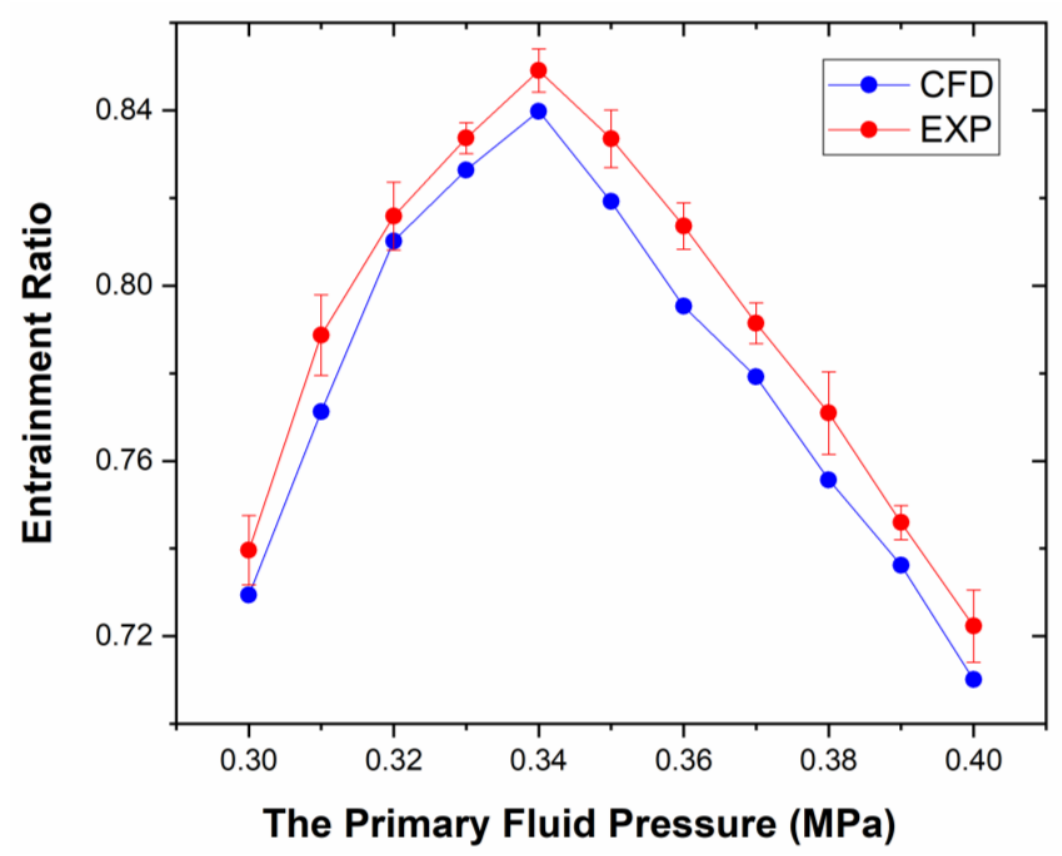

Figure 8. The variation of entrainment ratio with the primary fluid pressure.

\subsection{Effect of the Shock Wave on the Critical Back Pressure}

When the secondary fluid pressure and the back pressure are $1710 \mathrm{~Pa}$ and $3000 \mathrm{~Pa}$, respectively, the variation curve of the entrainment ratio and the back pressure under different primary fluid pressure is shown in Figure 9. According to the previous analysis, the increasing of the primary fluid pressure will cause the normal shock wave moves downstream close to the outlet of the ejector. Meanwhile, the Mach number in the upstream region of the shock wave is also raised (as shown in Figure 7). The structure of the shock wave develops from the inviscid normal shock with lower intensity to the bifurcated oblique shock with higher intensity (as shown in Figure 6). The critical back pressure enlarges with the increasing of the primary fluid pressure, while the entrainment ratio declines. When the primary fluid pressure is $0.34 \mathrm{MPa}$, the critical back pressure is $3200 \mathrm{~Pa}$; the critical back pressure is $6000 \mathrm{~Pa}$ as the primary fluid pressure is $0.46 \mathrm{MPa}$, increasing by nearly $47 \%$. To ensure the stable operation of the experimental system, a higher primary fluid pressure should be selected as far as possible within the allowable range of the experimental equipment. When the primary fluid pressure is $0.34 \mathrm{MPa}$, the entrainment ratio is 0.84 ; the entrainment ratio is $0.44 \mathrm{~Pa}$, as the primary fluid pressure is $0.46 \mathrm{MPa}$, which decreases by nearly $48 \%$. The critical back pressure is one of the main parameters to determine the working range of the ejector while the entrainment ratio is the parameter to determine the pumping efficiency of the ejector. In the case of ensuring the high pumping efficiency of the ejector, the primary fluid pressure can be appropriately increased to expand the operable range of the ejector.

As shown in Figure 10, when the primary fluid pressure is less than $0.40 \mathrm{MPa}$, the growth rate of critical back pressure is lower than the value when the primary fluid pressure is more than $0.40 \mathrm{MPa}$. The reason may be that the higher the primary fluid pressure is, the smaller the loss of momentum and kinetic energy produced by the mixed fluid. With the increase of the velocity and the intensity of the shock waves, the mixed fluid resisting the back pressure disturbance is improved. The analysis combined with Figures 6 and 9; the growth rate of the critical back pressure is related to the length of the pseudo-shock wave region. Moreover, the longer the pseudo-shock wave length results in the greater value of the critical back pressure. It indicates that the pseudo-shock wave region has a very significant influence on the critical back pressure. The growth rate of critical back pressure also is related to the primary fluid pressure. When the primary fluid pressure is kept in $0.32 \mathrm{MPa}-0.40 \mathrm{MPa}$, the critical back pressure cure shows a slope of $\mathrm{M} 1=0.0012$. The slope of the critical back pressure increases to $\mathrm{M} 2=0.0031$ when the critical back pressure varies between $0.40 \mathrm{MPa}-0.46 \mathrm{MPa}$. The growth rate of the 
critical back pressure at $0.40 \mathrm{MPa}-0.46 \mathrm{MPa}$ accelerates $61 \%$ comparing with the $0.32 \mathrm{MPa}-0.40 \mathrm{MPa}$. Consequently, though the critical back pressure is not constantly increased with the primary fluid pressure at the same growth rate.

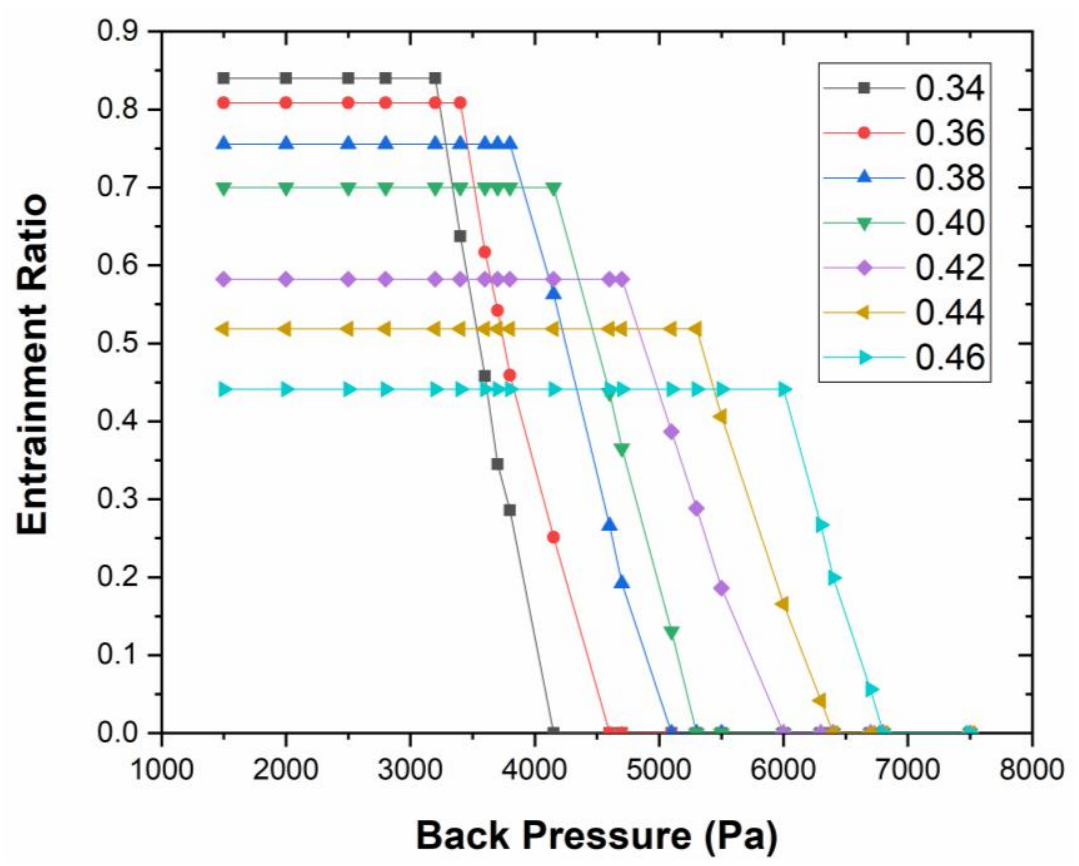

Figure 9. The relationship between entrainment ratio and back pressure under the primary fluid pressure.

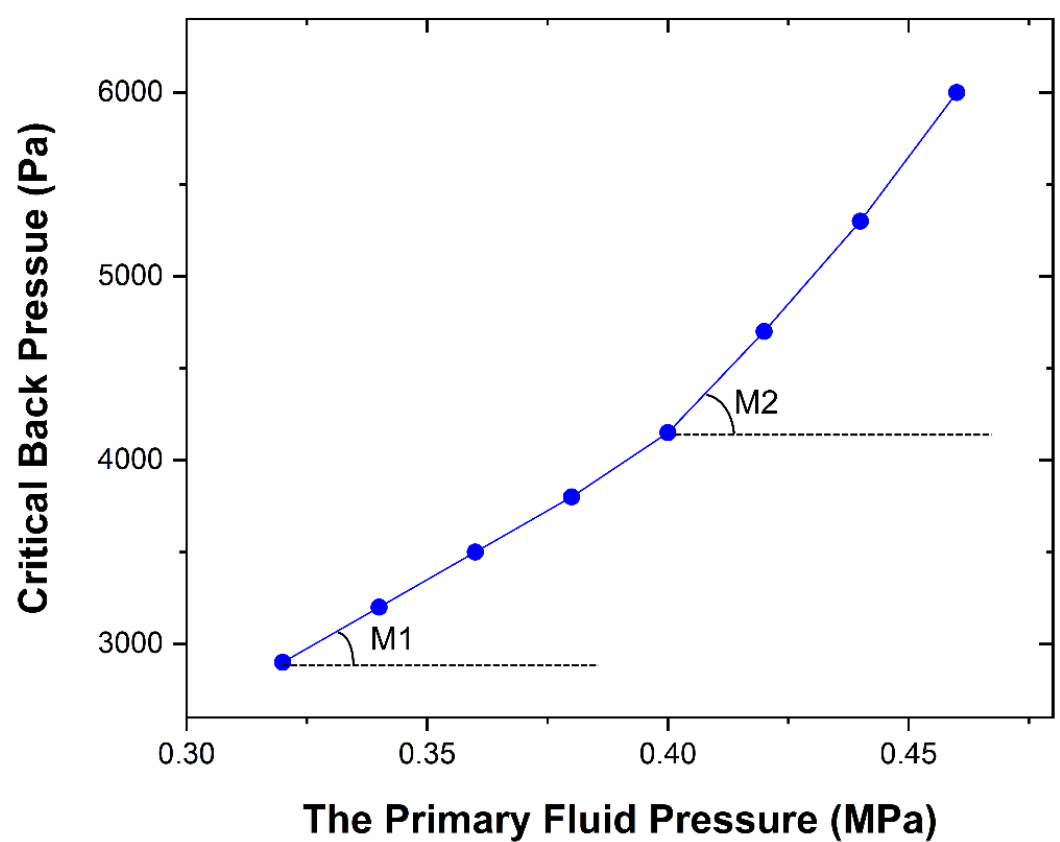

Figure 10. The influence of the primary fluid pressure on critical back pressure.

The disturbance caused by the back pressure propagates the inverse pressure gradient from the downstream to the upstream. When the reverse pressure value is lower than the critical back pressure, the shock wave will offset the disturbance caused by the reverse pressure value and decrease the energy loss. Simultaneously, with the increasing of the back pressure, the energy and intensity of the normal shock wave will decrease, the shock wave structure will be changed. Once the adverse pressure gradient value is higher than the critical back pressure value, the adverse pressure gradient will continue to move upstream and cause no normal shock wave to be generated. The inverse pressure 
gradient will directly enter the throat section and destroy the formation of choking flow where results in the flow passage of contraction structure not being produced, and the secondary fluid cannot be pumped into the mixing chamber. As a result, the pumping performance of the ejector will drop sharply until the ejector loses efficiency.

\section{Conclusions}

In this work, the engine combustion waste heat as the heat source is driven by the steam ejector refrigeration system, which can improve the energy utilization and save cost, as is proposed. The effect of the shock wave structure on the pumping performance of the steam ejector is thoroughly studied. The shock train and co-velocity region locating in the mixing chamber and throat sections is defined as the pseudo-shock region. While the other part is the oblique-shock region consisting of a single normal shock wave and a series of the oblique shock waves locating in the subsonic diffuser section. The shock train, the single normal shock wave and the oblique shock wave are the three types of shock waves, respectively. In conclusion, the main findings of this study are as follows: (i) the shock wave structure is thoroughly studied by the experimental-CFD method. An experimental system of the ejector refrigeration was established and the CFD model was verified. Based on the ideal gas model, the k-w SST turbulence model is chosen, as it can predict the complex flow in the ejector; (ii) the structure of the shock wave is divided into two regions: pseudo-shock region and the oblique-shock region. Three types of shock waves are determined as the shock train, the normal shock wave and the oblique shock wave, respectively; (iii) the length of the pseudo-shock region increases with the increasing of the primary fluid pressure when the pressure is less than $0.34 \mathrm{MPa}$, then maintains constant. Due to a part of the energy of the mixed fluid is consumed, the entrainment ratio and the pumping performance of the steam ejector decreases. The bifurcation shock waves increase, and the energy of the normal shock wave decreases with the increase of the primary fluid pressure when the primary fluid pressure is more than $0.34 \mathrm{MPa}$; (iv) as the primary fluid pressure increases, the entrainment ratio declines and the critical back pressure and the length of shock waves increasing of the steam ejector increase; (v) the idealized primary fluid pressure is between $0.32 \mathrm{MPa}$ and $0.36 \mathrm{MPa}$ and the idealized Mach number is between 1.6 and 2.1. The growth rate of the critical back pressure with the primary fluid pressure at $0.40 \mathrm{MPa}-0.46 \mathrm{MPa}$ accelerates $61 \%$ compared with the pressure at $0.32 \mathrm{MPa}-0.40 \mathrm{MPa}$. With the utilization of CFD analysis, the critical operating primary fluid pressure of the steam ejector system was identified. It can enhance the effectiveness of converting combustion waste heat to recyclable and useful energy sources in a steam ejector refrigeration system. Future works can be carried out to further enhance the understanding of the shock structure via experimentation using high-speed photography techniques.

Author Contributions: Conceptualization, Y.H. and X.W.; algorithm, Y.H. and L.G.; software, Y.H., C.W., R.C. and H.L.; data curation, Y.H., A.C.Y.Y. and H.L.; formal analysis, Y.H. and A.C.Y.Y.; numerical simulations, Y.H. and X.W.; validation, A.C.Y.Y., C.L. and; writing—original draft preparation, Y.H. and X.W.; writing—review and editing, A.C.Y.Y., L.G., R.C. and H.L.; visualization, L.G. and R.C.; supervision, J.T. and G.H.Y.; funding acquisition, X.W., J.T. and G.H.Y.

Funding: This research was funded by the National Natural Science Foundation of China (51775098), the Australian Research Council (DP160101953) and the Australian Research Council Industrial Transformation Training Centre (ARC IC170100032) in the University of New South Wale. All financial and technical support are deeply appreciated by the authors.

Conflicts of Interest: The authors declare no conflict of interest.

\section{References}

1. Dong, J.; Yu, M.; Wang, W.; Song, H.; Li, C.; Pan, X. Experimental investigation on low-temperature thermal energy driven steam ejector refrigeration system for cooling application. Appl. Therm. Eng. 2017, 123, 167-176. [CrossRef]

2. Eames, I.W.; Aphornratana, S.; Haider, H. A theoretical and experimental study of a small-scale steam jet refrigerator. Int. J. Refrig. 1995, 18, 378-386. [CrossRef] 
3. Besagni, G.; Mereu, R.; Inzoli, F. Ejector refrigeration: A comprehensive review. Renew. Sustain. Energy Rev. 2016, 53, 373-407. [CrossRef]

4. Wu, Y.; Zhao, H.; Zhang, C.; Wang, L.; Han, J. Optimization analysis of structure parameters of steam ejector based on CFD and orthogonal test. Energy 2018, 151, 79-93. [CrossRef]

5. Li, A.; Yuen, A.C.Y.; Chen, T.B.Y.; Wang, C.; Liu, H.; Cao, R.; Yang, W.; Yeoh, G.H.; Timchenko, V. Computational study of wet steam flow to optimize steam ejector efficiency for potential fire suppression application. Appl. Sci. 2019, 9, 1486. [CrossRef]

6. Chen, Y.M.; Sun, C.Y. Experimental Study of the Performance Characteristics of a Steam-Ejector Refrigeration System. Exp. Therm. Fluid Sci. 1997, 15, 384-394. [CrossRef]

7. Aphornratana, S.; Eames, I.W. A small capacity steam-ejector refrigerator: Experimental investigation of a system using ejector with movable primary nozzle. Int. J. Refrig. 1997, 20, 352-358. [CrossRef]

8. Eames, I.W.; Wu, S.; Worall, M.; Aphornratana, S. An experimental investigation of steam ejectors for applications in jet-pump refrigerators powered by low-grade heat. Proc. Inst. Mech. Eng. Part A J. Power Energy 1999, 213, 351-361. [CrossRef]

9. Chunnanond, K.; Aphornratana, S. An experimental investigation of a steam ejector refrigerator: The analysis of the pressure profile along the ejector. Appl. Therm. Eng. 2004, 24, 311-322. [CrossRef]

10. Ma, X.; Zhang, W.; Omer, S.A.; Riffat, S.B. Experimental investigation of a novel steam ejector refrigerator suitable for solar energy applications. Appl. Therm. Eng. 2010, 30, 1320-1325. [CrossRef]

11. Varga, S.; Oliveira, A.C.; Ma, X.; Omer, S.A.; Zhang, W.; Riffat, S.B. Comparison of CFD and experimental performance results of a variable area ratio steam ejector. Int. J. Low-Carbon Technol. 2011, 6, 119-124. [CrossRef]

12. Varga, S.; Oliveira, A.C.; Ma, X.; Omer, S.A.; Zhang, W.; Riffat, S.B. Experimental and numerical analysis of a variable area ratio steam ejector. Int. J. Refrig. 2011, 34, 1668-1675. [CrossRef]

13. Chandra, V.V.; Ahmed, M.R. Experimental and computational studies on a steam jet refrigeration system with constant area and variable area ejectors. Energy Convers. Manag. 2014, 79, 377-386. [CrossRef]

14. Ramesh, A.S.; Joseph Sekhar, S. Experimental Studies on the Effect of Suction Chamber Angle on the Entrainment of Passive Fluid in a Steam Ejector. J. Fluids Eng. 2017, 140, 011106. [CrossRef]

15. Ramesh, A.S.; Sekhar, S.J. Experimental and numerical investigations on the effect of suction chamber angle and nozzle exit position of a steam-jet ejector. Energy 2018, 164, 1097-1113. [CrossRef]

16. Li, F.; Li, R.; Li, X.; Tian, Q. Experimental investigation on a R134a ejector refrigeration system under overall modes. Appl. Therm. Eng. 2018, 137, 784-791. [CrossRef]

17. Dong, J.; Chen, X.; Wang, W.; Kang, C.; Ma, H. An experimental investigation of steam ejector refrigeration system powered by extra low temperature heat source. Int. Commun. Heat Mass Transf. 2017, 81, 250-256. [CrossRef]

18. Śmierciew, K.; Gagan, J.; Butrymowicz, D.; Łukaszuk, M.; Kubiczek, H. Experimental investigation of the first prototype ejector refrigeration system with HFO-1234ze(E). Appl. Therm. Eng. 2017, 110, 115-125. [CrossRef]

19. Wang, X.; Dong, J.; Li, A.; Lei, H.; Tu, J. Numerical study of primary steam superheating effects on steam ejector flow and its pumping performance. Energy 2014, 78, 205-211. [CrossRef]

20. Yuen, A.; Chen, T.; Yang, W.; Wang, C.; Li, A.; Yeoh, G.; Chan, Q.; Chan, M. Natural Ventilated Smoke Control Simulation Case Study Using Different Settings of Smoke Vents and Curtains in a Large Atrium. Fire 2019, 2, 7. [CrossRef]

21. Yuen, A.C.Y.; Yeoh, G.H.; Cheung, S.C.P.; Chan, Q.N.; Chen, T.B.Y.; Yang, W.; Lu, H. Numerical study of the development and angular speed of a small-scale fire whirl. J. Comput. Sci. 2018, 27, 21-34. [CrossRef]

22. Yuen, A.C.Y.; Yeoh, G.H.; Timchenko, V.; Cheung, S.C.P.; Chen, T. Study of three LES subgrid-scale turbulence models for predictions of heat and mass transfer in large-scale compartment fires. Numer. Heat Transf. Part A Appl. 2016, 69, 1223-1241. [CrossRef]

23. Chen, T.B.Y.; Yuen, A.C.Y.; Wang, C.; Yeoh, G.H.; Timchenko, V.; Cheung, S.C.P.; Chan, Q.N.; Yang, W. Predicting the fire spread rate of a sloped pine needle board utilizing pyrolysis modelling with detailed gas-phase combustion. Int. J. Heat Mass Transf. 2018, 125, 310-322. [CrossRef]

24. Fu, W.; Liu, Z.; Li, Y.; Wu, H.; Tang, Y. Numerical study for the influences of primary steam nozzle distance and mixing chamber throat diameter on steam ejector performance. Int. J. Therm. Sci. 2018, 132, 509-516. [CrossRef] 
25. Varga, S.; Oliveira, A.C.; Diaconu, B. Numerical assessment of steam ejector efficiencies using CFD. Int. J. Refrig. 2009, 32, 1203-1211. [CrossRef]

26. Yuan, Y.; Tan, L.; Xu, Y.; Yuan, Y. Three-dimensional CFD modeling and simulation on the performance of steam ejector heat pump for dryer section of the paper machine. Vacuum 2015, 122, 168-178. [CrossRef]

27. Dong, J.; Wang, W.; Han, Z.; Ma, H.; Deng, Y.; Su, F.; Pan, X. Experimental investigation of the steam ejector in a single-effect thermal vapor compression desalination system driven by a low-temperature heat source. Energies 2018, 11, 2282. [CrossRef]

28. Zhang, K.; Zhu, X.; Ren, X.; Qiu, Q.; Shen, S. Numerical investigation on the effect of nozzle position for design of high performance ejector. Appl. Therm. Eng. 2017, 126, 594-601. [CrossRef]

29. Varga, S.; Oliveira, A.C.; Diaconu, B. Influence of geometrical factors on steam ejector performance-A numerical assessment. Int. J. Refrig. 2009, 32, 1694-1701. [CrossRef]

30. Li, X.; Wang, T.; Day, B. Numerical analysis of the performance of a thermal ejector in a steam evaporator. Appl. Therm. Eng. 2010, 30, 2708-2717. [CrossRef]

31. Wu, H.; Liu, Z.; Han, B.; Li, Y. Numerical investigation of the influences of mixing chamber geometries on steam ejector performance. Desalination 2014, 353, 15-20. [CrossRef]

32. Yang, X.; Long, X.; Yao, X. Numerical investigation on the mixing process in a steam ejector with different nozzle structures. Int. J. Therm. Sci. 2012, 56, 95-106. [CrossRef]

33. Ruangtrakoon, N.; Thongtip, T.; Aphornratana, S.; Sriveerakul, T. CFD simulation on the effect of primary nozzle geometries for a steam ejector in refrigeration cycle. Int. J. Therm. Sci. 2013, 63, 133-145. [CrossRef]

34. Riffat, S.B.; Omer, S.A. CFD modelling and experimental investigation of an ejector refrigeration system using methanol as the working fluid. Int. J. Energy Res. 2001, 25, 115-128. [CrossRef]

35. Sriveerakul, T.; Aphornratana, S.; Chunnanond, K. Performance prediction of steam ejector using computational fluid dynamics: Part 1. Validation of the CFD results. Int. J. Therm. Sci. 2007, 46, 812-822. [CrossRef]

36. Sriveerakul, T.; Aphornratana, S.; Chunnanond, K. Performance prediction of steam ejector using computational fluid dynamics: Part 2. Flow structure of a steam ejector influenced by operating pressures and geometries. Int. J. Therm. Sci. 2007, 46, 823-833. [CrossRef]

37. Aly, N.H.; Karameldin, A.; Shamloul, M.M. Modelling and simulation of steam jet ejectors. Desalination 1999, 123, 1-8. [CrossRef]

38. Su, L.; Agarwal, R.K. CFD Simulation of a Supersonic Steam Ejector for Refrigeration Application. In Proceedings of the ASME/JSME/KSME 2015 Joint Fluids Engineering Conference, Seoul, Korea, 26-31 July 2015.

39. Desevaux, P.; Mellal, A.; Alves de Sousa, Y. Visualization of secondary flow choking phenomena in a supersonic air ejector. J. Vis. 2004, 7, 249-256. [CrossRef]

40. Matsuo, K. Shock train and pseudo-shock phenomena in supersonic internal flows. J. Therm. Sci. 2003, 12, 204-208. [CrossRef]

41. Han, Y.; Wang, X.; Sun, H.; Zhang, G.; Guo, L.; Tu, J. CFD simulation on the boundary layer separation in the steam ejector and its influence on the pumping performance. Energy 2019, 167, 469-483. [CrossRef]

42. Ariafar, K.; Buttsworth, D.; Al-Doori, G.; Sharifi, N. Mixing layer effects on the entrainment ratio in steam ejectors through ideal gas computational simulations. Energy 2016, 95, 380-392. [CrossRef]

43. Wang, X.; Dong, J.; Zhang, G.; Fu, Q.; Li, H.; Han, Y.; Tu, J. The primary pseudo-shock pattern of steam ejector and its influence on pumping efficiency based on CFD approach. Energy 2019, 167, 224-234. [CrossRef]

44. Wang, X.; Dong, J.; Lei, H.; Li, A.; Wang, R.; Chen, W.; Tu, J. Modeling and simulation of steam-jet vacuum pump. Zhenkong Kexue yu Jishu Xuebao/Vacuum Sci. Technol. 2013, 33, 1069-1073.

45. Yuen, A.C.Y.; Yeoh, G.H.; Timchenko, V.; Chen, T.B.Y.; Chan, Q.N.; Wang, C.; Li, D.D. Comparison of detailed soot formation models for sooty and non-sooty flames in an under-ventilated ISO room. Int. J. Heat Mass Transf. 2017, 115, 717-729. [CrossRef]

46. Yuen, A.C.Y.; Yeoh, G.H.; Timchenko, V.; Cheung, S.C.P.; Barber, T.J. Importance of detailed chemical kinetics on combustion and soot modelling of ventilated and under-ventilated fires in compartment. Int. J. Heat Mass Transf. 2016, 96, 171-188. [CrossRef]

47. Li, A.; Yeoh, G.H.; Timchenko, V.; Yuen, A.C.Y.; Wang, X. Numerical Study of Condensation Effect on a Steam Ejector by Wet Steam Model. In Proceedings of the Thirteenth International Conference on Flow Dynamics (ICFD2016), Sendai, Japan, 10-12 October 2016; Volume 12, pp. 492-493. 
48. Chen, T.B.Y.; Yuen, A.C.Y.; Yeoh, G.H.; Timchenko, V.; Cheung, S.C.P.; Chan, Q.N.; Yang, W.; Lu, H. Numerical study of fire spread using the level-set method with large eddy simulation incorporating detailed chemical kinetics gas-phase combustion model. J. Comput. Sci. 2018, 24, 8-23. [CrossRef]

49. Yuen, A.C.Y.; Chen, T.B.Y.; Yeoh, G.H.; Yang, W.; Cheung, S.C.P.; Cook, M.; Yu, B.; Chan, Q.N.; Yip, H.L. Establishing pyrolysis kinetics for the modelling of the flammability and burning characteristics of solid combustible materials. J. Fire Sci. 2018, 36, 494-517. [CrossRef]

50. Yuen, A.C.Y.; Yeoh, G.H. Numerical simulation of an enclosure fire in a large test hall. Comput. Therm. Sci. 2013, 5, 459-471. [CrossRef]

51. Yuen, A.C.Y.; Yeoh, G.H.; Timchenko, V.; Cheung, S.C.P.; Chan, Q.N.; Chen, T. On the influences of key modelling constants of large eddy simulations for large-scale compartment fires predictions. Int. J. Comut. Fluid Dyn. 2017, 31, 324-337. [CrossRef]

52. Besagni, G.; Mereu, R.; Inzoli, F. CFD study of ejector flow behavior in a blast furnace gas galvanizing plant. J. Therm. Sci. 2015, 24, 58-66. [CrossRef]

53. Besagni, G.; Mereu, R.; Chiesa, P.; Inzoli, F. An Integrated Lumped Parameter-CFD approach for off-design ejector performance evaluation. Energy Convers. Manag. 2015, 105, 697-715. [CrossRef]

54. Crocco, L. One-dimensional treatment of steady gas dynamics. Fundam. Gas Dyn. 1958, Chap-B, 64-349.

55. Huang, B.J.; Chang, J.M.; Wang, C.P.; Petrenko, V.A. 1-D analysis of ejector performance. Int. J. Refrig. 1999, 22, 354-364. [CrossRef]

(C) 2019 by the authors. Licensee MDPI, Basel, Switzerland. This article is an open access article distributed under the terms and conditions of the Creative Commons Attribution (CC BY) license (http://creativecommons.org/licenses/by/4.0/). 